\title{
ОЦЕНКА ГУМУСНОГО СОСТОЯНИЯ ПОЧВ ЕСТЕСТВЕННЫХ ЭКОСИСТЕМ ОСНОВНЫХ ПОЧВЕННО-ГЕОГРАФИЧЕСКИХ ЗОН КУЗБАССА
}

\author{
V.P. Seredina, S.V. Ovsyannikova
}

\section{THE ASSESSMENT OF HUMUS STATE OF SOILS OF NATURAL ECOSYSTEMS OF THE MAIN SOIL AND GEOGRAPHICAL ZONES OF KUZBASS}

Середина В.П. - д-р биол. наук, проф. кафр. почвоведения и экологии почв Национального исследовательского Томского государственного университета, г. Томск.

E-mail: seredina_v@mail.ru

Овсянникова С.В. - канд. биол. наук, доц. каф. автомобильных дорог и городского кадастра Кузбасского государственного технического университета им. Т.Ф. Горбачева, г. Кемерово.

E-mail: sv_ovsyannikova@mail.ru

Цель исследований - оценка современного гумусного состояния почв в пределах опорных пунктов (ОП) мониторинеа, приуроченных к основным промышленным районам Кузбасса. Задачи: изучение содержания и общих запасов органического вещества, особенностей качественного состава и основных параметров гумусного состояния почв. ОП характеризуют определенную зону: лесостепь Кузнецкой котловины, островную лесостепь, степное ядро Кузнецкой котловины, зону лесостепи предгорий, Мариинско-Ачинский почвенны й округ расчлененной лесостепи и лесостепи предгорий. Почвы ОП относятся к отделам текстурнодифрференцированных и аккумулятивногумусовых почв постлитогенного ствола. Для исследованных дерново-подзолистых почв, как и для всех западносибирских почв подзолистого ряда, характерно некоторое замедление и нескомпенсированность биологического круговорота веществ и, как следствие, средняя степень гумификации органического вещества (29-30 \%), низкие запасы гумуса и низкая обогащенность гумуса азотом. Образование гуминовых кислот выражено слабо, тип гумуса - гуматно-фрульватный. Наиболее ценная фракция гумусовых кислот, связанная с кальцием, составляет незначительную часть ор-
Seredina V.P. - Dr. Biol. Sci., Prof., Chair of Soil Science and Ecology of Soil, National Research Tomsk State University, Tomsk.

E-mail: seredina_v@mail.ru

Ovsyannikova S.V. - Cand. Biol. Sci., Assoc. Prof., Chair of Highways and City Inventory, Kuzbass State Technical University named after T.F. Gorbachev, Kemerovo.

E-mail: sv_ovsyannikova@mail.ru

ганического углерода. В составе гумуса значительную долю составляет негидролизуемый остаток. В отличие от аналогичных почв европейской территории России исследованные почвы более гумусированы, гумус их обладает более высокой подвижностью. Процессы гумисикации в типе серых и темно-серых почв протекают при более благоприятном гидротермическом режиме, менее кислой реакции среды и более высокой биологической активности. Степень гумисрикации органического вещества высокая (34-39 \%), тип гумуса фульватно-гуматный. По мере перехода от серых к темно-серым почвам и черноземам обогащенность гумуса азотом изменяется от средней до высокой, увеличиваются содержание и запасы гумуса. В составе гумуса возрастает количество гуминовых кислот, доминирующей фрракцией являются гуматы кальция, уменьшается подвижность гумуса. Основные показатели интегральной оценки гумусного состояния почв могут служить информативными фооновыми характеристиками, направленными на выявление их изменений в ходе антропедогенеза.

Ключевые слова: Кузбасс, почвы, гумус, групповой и фрракционный состав, гумусное состояние. 
The research goal is to evaluate the current soil humus condition within the limit of monitoring base stations (BS), associated with the primary industrial regions of Kuzbass. The tasks are to study the contents and general volume of organic substance; particularities of qualitative composition and basic parameters of soil humus state. BS characterize a certain zone: forest-steppe of Kuznetsk Depression, insular forest-steppe, steppe core of Kuznetsk Depression, the zone of foothill forest-steppe, Mariinsk-Achinsk soil district of segmented foreststeppe and the forest-steppe of foothills. The soils of $B S$ are related to texture-differentiated and accumulative-humus soils of post-lithogenous shafts. For researched sod-podzolic soils as well as for all West-Siberian podzolic soils of some retardation and non-compensated circulation of biological substance is characteristic, thereby the average level of organic substance humification (29-30\%), low level of humus volume and poor enrichment with nitrogen. Humic acids are poorly produced; humus type is humate-fulvatic. The most valuable fraction of humic acids is connected with calcium makes insignificant part of an organic carbon. A part of humus, its considerable share is made by nonhydrolyzed residue. Unlike similar soils of European territory of Russia, the researched soils are more humous, their humus is of higher mobility. The processes of humification of gray and darkgray soils run at favorable hydrothermal regime, less acid reaction of the environment and higher biological activity. The level of organic substance humification is high (34-39\%), the type of humus is fulvate-humatic. In the process of transition from gray to dark gray soils and chernozems humus enrichment with nitrogen changes from average to high, the contents and stocks of humus volume increase. The quantity of humic acids increases in the humus content; dominating fractures are lime humates, the humus mobility decreases. The main aspects of soil humus condition of integral evaluation can serve as an informative background characteristic that can reveal the changes occurring in the course of anthropogenesis.

Keywords: Kuzbass, soil, humus, group and fractional structure, humus condition.

Введение. В соответствии с современными исследованиями [1, 2] среди важнейших фрункций гумусовых веществ в биосфере - аккумуля- тивной, транспортной, регуляторной, фризиологической - большая роль отводится протекторной функции, обеспечивающей буферность почвенной системы, особо важной для почв урбанизированных территорий. Изменение количества органического вещества в почве прямо связано с изменением большинства свойств почв, в том числе и плодородия, а также, наряду с прямой взаимосвязью, отражает влияние внешних негативных факторов, которые вызывают деградацию почв [3]. Иными словами, сохранение почвенного органического вещества обеспечивается в первую очередь не на молекулярном уровне, а на уровне экосистемы [1]. Кемеровская область представляет собой промышленную зону, центральную часть которой занимает Кузнецкий угольный бассейн, являющийся крупнейшим из эксплуатируемых на сегодняшний день угольных бассейнов России, на долю которого приходится почти $40 \%$ общей добычи и более 70 \% добычи коксующихся углей [4]. Угольные предприятия - это комплексный источник техногенного воздействия на окружающую среду, оказывающий непосредственное влияние на состояние почвенных экосистем [5]. Непрерывное использование природного ресурса почв, как центрального звена экосистем, вызывает необходимость усиления контроля за их состоянием. Контроль за содержанием гумуса входит в число основных задач почвенноэкологического мониторинга [3].

Цель исследования. Оценка современного гумусного состояния почв естественных экосистем, приуроченных к основным почвенногеографрическим зонам Кузбасса.

Задачи: изучение содержания общих запасов органического вещества, особенностей качественного состава и основных параметров гумусного состояния почв на стационарных площадках (опорных пунктах мониторинга).

Объекты и методы исследования. Несмотря на то что Кемеровская область по сибирским масштабам занимает сравнительно небольшую площадь, ее почвенный покров достаточно разнообразен. Объекты исследования расположены на основных опорных пунктах (стационарных площадках) мониторинга в пределах Кузнецкого угольного бассейна. Опорный пункт «Кемеровский» (ОП 3) характеризует лесостепь Кузнецкой котловины; «Ленинск- 
Кузнецкий»(ОП 4) и «Беловский» (ОП 5) - островную лесостепь, степное ядро Кузнецкой котловины; «Новокузнецкий» (ОП 4) - зону лесостепи предгорий. В соответствии с каждой зоной формируется определенный зональный тип почв. Мониторинговые площадки, согласно СанПиН 2.2.1/2.1.1.1200-03, располагаются на границах санитарно-защитных зон в зависимости от санитарной классификации предприятия. Почвы изучались с помощью полевого, сравнительно-географического и морфологического методов. При изучении почв использовались общепринятые методики [6]. Определение общего органического углерода и валового азота проводилось в испытательной лаборатории ООО «СГП-ЭКО» в соответствии с государственными стандартами (г. Кемерово, аттестат аккредитации RA.RU.21AФ08 от 20.06.2017). Групповой и фрракционный состав гумуса - по Пономаревой-Плотниковой [7]. Анализ выполнен в лаборатории кафедры почвоведения и экологии почв Биологического института ТГУ.
Оценка гумусного состояния почв сделана по Гришиной и Орлову [8].

Результаты исследования и их обсуждение. Проведенные исследования показали, что почвы опорных пунктов мониторинга, в соответствии с классификацией и диагностикой почв России [9], относятся к отделам текстурнодиффференцированных и аккумулятивногумусовых почв постлитогенного ствола. Отдел текстурно-диффференцированных почв представлен следующими типами: дерновоподзолистая темно-серая; отдел аккумулятивногумусовых - чернозем глинисто-иллювиальный. В числе органических веществ, формирующих гумус, наиболее специфичны гумусовые кислоты и их органо-минеральные производные. Они лежат в основе характеристик гумусного состояния почв. Изученный ряд почв в пределах опорных пунктов мониторинга дерновоподзолистых - черноземов довольно четко различается не только по морфологии, своим физико-химическим свойствам, но прежде всего по содержанию и запасам гумуса (табл. 1).

Таблица 1

\section{Запасы гумуса, соотношение C:N в исследованных почвах}

\begin{tabular}{|l|c|c|c|c|}
\hline \multirow{2}{*}{\multicolumn{1}{c|}{ Почва }} & \multicolumn{3}{|c|}{ Запасы, т/га } & \multirow{2}{*}{ С:N } \\
\cline { 2 - 4 } & $0-20 \mathrm{~cm}$ & $0-50 \mathrm{~cm}$ & $0-100 \mathrm{~cm}$ & \\
\hline Дерново-подзолистая & 56 & 94 & 146 & 11,2 \\
\hline Серая & 108 & 186 & 268 & 10,3 \\
\hline Темно-серая & 139 & 303 & 389 & 8,0 \\
\hline Чернозем & 116 & 252 & 390 & 10,5 \\
\hline
\end{tabular}

Исследованные дерново-подзолистые почвы имеют средней мощности подстилку и характеризуются низким содержанием и запасами гумуса. В метровом слое этих почв аккумулировано всего лишь 146 т/га гумуса. При этом около 40 \% всего запаса гумуса приходится на слой 020 см. В серых почвах, где процесс гумусонакопления ярко выражен, а процесс гумификации направлен в сторону образования сложных гумусовых веществ, запас гумуса в метровом слое, в соответствии с показателями [8], может быть оценен как высокий. Около $59 \%$ общего запаса гумуса в метровой толще приходится на верхний 0-20 см слой. Темно-серые почвы по запасам гумуса близки к черноземам. Аккумуляция гумуса в черноземах обусловлена разложением как наземного опада степной и луговостепной растительности под влиянием активной деятельности микроорганизмов, так и большим количеством корневых остатков. Запасы гумуса в черноземах достигают 310-390 т/га в метровом слое. Эти почвы отличаются от типа дерново-подзолистых и серых лесных не только общими размерами накопления гумуса, но и его качественным составом (табл. 2). 


\section{Фракционный состав гумуса исследованных почв}

\begin{tabular}{|c|c|c|c|c|c|c|c|c|c|c|c|c|}
\hline \multirow{2}{*}{$\begin{array}{c}\text { Гор-т, глу- } \\
\text { бина, см }\end{array}$} & \multirow{2}{*}{ C, $\%$} & \multicolumn{4}{|c|}{$\mathrm{C}_{\text {гк, }} \%$ от $\mathrm{C}_{\text {общ. }}$} & \multicolumn{5}{|c|}{$\mathrm{C}_{\phi к,} \%$ от $\mathrm{C}_{\text {общ. }}$} & \multirow{2}{*}{$\mathrm{HO}^{*}$} & \multirow{2}{*}{$\begin{array}{l}C_{\text {гк: }}: \\
C_{\phi \phi k}\end{array}$} \\
\hline & & 1 & 2 & 3 & сумма & $1 \mathrm{a}$ & 1 & 2 & 3 & сумма & & \\
\hline \multicolumn{13}{|c|}{ Дерново-подзолистая глееватая тяжелосуглинистая почва, ОП 6} \\
\hline EL 5-15 & 2,7 & 18 & 7 & 4 & 29 & 8 & 8 & 16 & 7 & 39 & 32 & 0,7 \\
\hline BEL25-35 & 1,8 & 10 & 5 & 5 & 20 & 8 & 14 & 13 & 10 & 45 & 35 & 0,4 \\
\hline BT47-57 & 1,4 & 6 & 3 & 4 & 13 & 9 & 18 & 10 & 11 & 48 & 40 & 0,3 \\
\hline BT5-75 & 0,6 & 4 & 2 & 6 & 12 & 9 & 21 & 9 & 15 & 54 & 36 & 0,2 \\
\hline BT90-100 & 0,4 & 2 & 1 & 5 & 8 & 9 & 21 & 8 & 15 & 53 & 38 & 0,2 \\
\hline \multicolumn{13}{|c|}{ Серая легкоглинистая почва, ОП 3} \\
\hline AY1-6 & 5,9 & 18 & 13 & 6 & 37 & 6 & 5 & 15 & 7 & 33 & 33 & 1,1 \\
\hline AU 6-12 & 5,5 & 16 & 11 & 4 & 31 & 6 & 8 & 14 & 9 & 37 & 34 & 0,8 \\
\hline AEL13-23 & 4,9 & 11 & 8 & 6 & 25 & 5 & 12 & 12 & 12 & 41 & 35 & 0,6 \\
\hline BEL 30-40 & 2,1 & 7 & 5 & 6 & 18 & 7 & 16 & 10 & 14 & 47 & 35 & 0,4 \\
\hline BT50-60 & 1,8 & 6 & 5 & 7 & 18 & 7 & 16 & 10 & 14 & 47 & 36 & 0,4 \\
\hline BT80-90 & 0,7 & 6 & 5 & 6 & 17 & 6 & 16 & 10 & 14 & 47 & 37 & 0,4 \\
\hline BT100-110 & 0,5 & 6 & 4 & 6 & 16 & 6 & 17 & 9 & 15 & 47 & 38 & 0,3 \\
\hline \multicolumn{13}{|c|}{ Темно-серая легкоглинистая почва, ОП 5} \\
\hline AU 2-12 & 6,9 & 16 & 22 & 2 & 40 & 5 & 4 & 14 & 4 & 27 & 35 & 1,5 \\
\hline AEL27-37 & 5,1 & 15 & 23 & 3 & 41 & 3 & 6 & 14 & 4 & 27 & 32 & 1,5 \\
\hline BEL 42-52 & 3,8 & 14 & 16 & 4 & 34 & 5 & 9 & 14 & 6 & 34 & 34 & 1,0 \\
\hline BT60-70 & 2,4 & 6 & 6 & 5 & 17 & 7 & 14 & 13 & 14 & 48 & 36 & 0,4 \\
\hline BT75-85 & 0,8 & 3 & 2 & 4 & 9 & 7 & 15 & 13 & 15 & 50 & 41 & 0,2 \\
\hline \multicolumn{13}{|c|}{ Чернозем глинисто-иллювиальный легкоглинистый, ОП 4} \\
\hline AU0-10 & 6,0 & 13 & 25 & 2 & 40 & 5 & 5 & 13 & 2 & 25 & 36 & 1,6 \\
\hline AU 23-33 & 4,2 & 13 & 26 & 3 & 42 & 2 & 5 & 12 & 2 & 21 & 38 & 2,0 \\
\hline $\mathrm{B} \mid 40-50$ & 3,9 & 10 & 30 & 2 & 42 & 4 & 5 & 12 & 4 & 25 & 34 & 1,7 \\
\hline Bl60-70 & 2,7 & 10 & 24 & 2 & 36 & 4 & 6 & 14 & 4 & 28 & 37 & 1,3 \\
\hline Bl85-95 & 1,1 & 8 & 19 & 5 & 32 & 4 & 10 & 14 & 8 & 36 & 34 & 0,9 \\
\hline
\end{tabular}

* $\mathrm{HO}$ - негидролизуемый остаток, \% от $\mathrm{C}_{\text {общ. }}$.

В составе гумуса дерново-подзолистых почв по всему профилю фульвокислоты значительно преобладают над гуминовыми кислотами. Аналогично подзолистым почвам средней тайги [10] образование гуминовых кислот выражено слабо. В верхнем горизонте данной почвы отношение Сгк:Сфк равно 0,7, что соответствует гуматно-фульвватному типу, с глубиной профиля сужаясь до 0,3-0,2, что указывает на фульватный тип. Степень гумификации органического вещества средняя (28-30\%), обогащенность гумуса азотом низкая (C: $\mathrm{N}=9-11)$. Для всех дерновоподзолистых почв (целинных) отмечается значительная подвижность гумуса. Об этом свидетельствует высокое содержание первой фракции гуминовых кислот, так называемой подвиж- ной или свободной. Величина негидролизуемого остатка минимальна в горизонте EL с тенденцией возрастания в нижележащих горизонтах. Наименьшей подвижностью (растворимостью) система гумусовых веществ характеризуется в горизонтах ВТ, где относительная доля гумина составляет около $40 \%$.

В верхних горизонтах серых и темно-серых почв тип гумуса фульватно-гуматный. Нижняя часть профиля отличается накоплением в нем фульвокислот. Поскольку они являются водорастворимыми веществами, то их накопление в нижней части профиля является результатом процесса вымывания из верхних слоев почвы. Степень гумификации органического вещества высокая (34-39 \%), обогащенность гумуса азо- 
том изменяется от средней в серых почвах до высокой в темно-серых. Выявлено, что по мере перехода от серых к темно-серым почвам в составе гумуса увеличивается количество гуминовых кислот, особенно второй фракции, связанной с кальцием, то есть происходит нарастание признаков, свойственных черноземам.

В составе гумуса черноземов гуминовые кислоты преобладают над фульвокислотами (отношение Сгк:Сфрк равно 1,6-1,9). Степень гумификации органического вещества высокая и очень высокая. Среди гуминовых кислот и фульвокислот преобладают фрракции, связанные с кальцием (относительная доля данной фрракции от суммы ГК 62-68 \%). Содержание подвижных фрорм гумусовых кислот невелико. Обогащенность гумуса азотом высокая. Распределение относительного содержания нерастворимого остатка по профилю является зеркальным отражением профильного распределения фрракций гумусовых кислот.

Таким образом, основные показатели интегральной оценки гумусного состояния почв (содержание, запасы, фрракционно-групповой состав) могут быть использованы как информативные фоновые характеристики для проведения почвенного экологического мониторинга.

\section{Выводы}

1. Известно, что по основным параметрам гумусного состояния почвы опорных пунктов мониторинга характеризуются отчетливо выраженными различиями. Характерными особенностями гумусного состояния дерновоподзолистых почв являются гуматнофульватный тип гумуса, средняя степень гумификации органического вещества (29-30\%), низкое содержание и запасы гумуса и низкая обогащенность гумуса азотом. Преобладающей фракцией гуминовых кислот является первая, представленная бурыми гуминовыми кислотами, свободными и непрочно связанными с полуторными оксидами. Наиболее ценная фракция гумусовых кислот, связанная с кальцием, составляет незначительную часть органического углерода.

2. Групповой состав гумуса серых почв характеризуется близкими долями гуминовых (ГК) и фульвокислот (ФК) в верхнем 25- сантиметровом слое (горизонты,AY,AU, AEL), в связи с чем отношение углерода ГК к углероду ФК близко к 1 (тип гумуса фульватно-гуматный). В нижних горизонтах значение $\mathrm{C}_{\text {гк. }}: \mathrm{C}_{\text {фк }}$ Снижается до 0,3-0,2 (тип гумуса фульватный). Отмечается средняя обогащенность гумуса азотом $(\mathrm{C}: \mathrm{N}=9-10)$.

3. По мере перехода от серых к темно-серым почвам и черноземам отмечаются закономерные изменения основных показателей гумусного состояния почв: усиливается интенсивность процессов гумификкации, обогащенность гумуса азотом изменяется от средней до высокой, увеличиваются содержание и запасы гумуса. В составе гумуса темно-серых почв и черноземов глинисто-иллювиальных отмечается большее накопление гуминовых кислот, преобладающих по всему профилю. Доля их составляет 39-41 \% от общего содержания органического углерода. Доминирующей фрракцией являются гуматы кальция, уменьшается подвижность гумуса.

\section{Литература}

1. Семенов В.М., Когут Б.М. Почвенное органическое вещество. - М.: ГЕОС, 2015. - 233 с.

2. Smidt M.W.I., Abiven S. [et al.]. Persistese of soil organic matteras an ecosystem property $/ 1$ Nature. - 2011. - V. 478. - P. 49-56.

3. Деградация и охрана почв / под общ. ред. Г.В. Добровольского. - М.: Изд-во МГУ, 2002. -654 C.

4. Куприянов А.Н., Манаков Ю., Баранник Л.П. Восстановление экосистем на отвалах горнодобывающей промышленности Кузбасса. - Новосибирск: Гео, 2010. - 160 с.

5. Овсянникова С.В., Середина В.П., Шайхутдинова А.Н. Тяжелые металлы и радионуклиды в почвах Кузбасса: состояние и экологическая оценка. - Кемерово: Изд-во КузГТУ, 2016. - 246 c.

6. Теория и практика химического анализа почв / под ред. Л.А. Воробьевой. - М.: ГEOC, 2006. - $400 \mathrm{c}$.

7. Пономарева В.В., Плотникова Т.А. Гумус и почвообразование. - Л.: Наука, 1980. - 221 с.

8. Гришина Л.А. Гумусообразование и гумусное состояние почв. - М.: Изд-во МГУ, 1986. $-243 \mathrm{c}$. 
9. Классификация и диагностика почв России / Л.Л. Титов, В.Д. Тонконогов, И.И. Лебедев [и др.]. - Смоленск: Ойкумена, 2004. - 342 с.

10. Середина В.П., Непотребный А.И. Гумус фоновых почв Вахского нефтяного месторождения (средняя тайга Западной Сибири) // Вестник КрасГАУ. - 2017. - № 8. - С. 82-87.

\section{Literatura}

1. Semenov V.M., Kogut B.M. Pochvennoe organicheskoe veshhestvo. - M.: GEOS, 2015. - $233 \mathrm{~s}$.

2. Smidt M.W.I., Abiven S. [et al.]. Persistese of soil organic matteras an ecosystem property $/ 1$ Nature. - 2011. - V. 478. - P. 49-56.

3. Degradacija i ohrana pochv / pod obshh. red. G.V. Dobrovol'skogo. - M.: Izd-vo MGU, 2002. - $654 \mathrm{~s}$.

4. Kuprijanov A.N., Manakov Ju., Barannik L.P. Vosstanovlenie jekosistem na otvalah gornodobyvajushhej promyshlennosti Kuzbassa. - Novosibirsk: Geo, 2010. - 160 s.
5. Ovsjannikova S.V., Seredina V.P., Shajhutdinova A.N. Tjazhelye metally i radionuklidy v pochvah Kuzbassa: sostojanie i jekologicheskaja ocenka. - Kemerovo: Izd-vo KuzGTU, 2016. - $246 \mathrm{~s}$.

6. Teorija i praktika himicheskogo analiza pochv / pod red. L.A. Vorob'evoj. - M.: GEOS, 2006. $400 \mathrm{~s}$.

7. Ponomareva V.V., Plotnikova T.A. Gumus i pochvoobrazovanie. - L.: Nauka, 1980. - $221 \mathrm{~s}$.

8. Grishina L.A. Gumusoobrazovanie i gumusnoe sostojanie pochv. - M.: Izd-vo MGU, 1986. $243 \mathrm{~s}$.

9. Klassifikacija i diagnostika pochv Rossii / L.L. Titov, V.D. Tonkonogov, I.I. Lebedev [i dr.]. - Smolensk: Ojkumena, 2004. - $342 \mathrm{~s}$.

10. Seredina V.P., Nepotrebnyj A.I. Gumus fonovyh pochv Vahskogo neftjanogo mestorozhdenija (srednjaja tajga Zapadnoj Sibiri) // Vestnik KrasGAU. - 2017. - № 8. S. 82-87. 